\title{
Screening and identification of key biomarkers in hepatocellular carcinoma: Evidence from bioinformatic analysis
}

\author{
LIN LI $^{*}$, QINGSONG LEI ${ }^{1 *}$, SHUJUN ZHANG ${ }^{1}$, LINGNA KONG $^{2}$ and BO QIN ${ }^{1}$ \\ ${ }^{1}$ Department of Infectious Diseases, The First Affiliated Hospital of Chongqing Medical University; \\ ${ }^{2}$ The Nursing College of Chongqing Medical University, Yuzhong, Chongqing 400016, P.R. China
}

Received February 14, 2017; Accepted May 18, 2017

DOI: 10.3892/or.2017.5946

\begin{abstract}
Hepatocellular carcinoma (HCC) is one of the most common cancers worldwide. Intense efforts have been made to elucidate the pathogeny, but the molecular mechanisms of HCC are still not well understood. To identify the candidate genes in the carcinogenesis and progression of HCC, microarray datasets GSE19665, GSE33006 and GSE41804 were downloaded from Gene Expression Omnibus (GEO) database. The differentially expressed genes (DEGs) were identified, and function enrichment analyses were performed. The protein-protein interaction network (PPI) was constructed and the module analysis was performed using STRING and Cytoscape. A total of 273 DEGs were identified, consisting of 189 downregulated genes and 84 upregulated genes. The enriched functions and pathways of the DEGs include protein activation cascade, complement activation, carbohydrate binding, complement and coagulation cascades, mitotic cell cycle and oocyte meiosis. Sixteen hub genes were identified and biological process analysis revealed that these genes were mainly enriched in cell division, cell cycle and nuclear division. Survival analysis showed that BUB1, CDC20, KIF20A, RACGAP1 and CEP55 may be involved in the carcinogenesis, invasion or recurrence of HCC. In conclusion, DEGs and hub genes identified in the present study help us understand the molecular mechanisms underlying the carcinogenesis and progression of HCC, and provide candidate targets for diagnosis and treatment of HCC.
\end{abstract}

\section{Introduction}

Hepatocellular carcinoma (HCC), mainly induced by chronic hepatitis $\mathrm{B}$ virus (HBV) or hepatitis $\mathrm{C}$ virus ( $\mathrm{HCV}$ ) infection,

Correspondence to: Dr Bo Qin, Department of Infectious Diseases, The First Affiliated Hospital of Chongqing Medical University, 1 Youyi Road, Yuzhong, Chongqing 400016, P.R. China E-mail: cqqinbo@126.com

*Contributed equally

Key words: hepatocellular carcinoma, differentially expressed genes, microarray, protein-protein interaction, Kaplan-Meier curve hepatic cirrhosis or alcoholic liver diseases, is one of the most common malignancies with a rise in new cases worldwide each year. HCC has a higher rate in developing countries partly East Asia as compared to developed countries (1). Accumulating evidence has demonstrated that abnormal expression and mutation of genes are involved in the carcinogenesis and progression of $\mathrm{HCC}$, including cyclin D1 (CCND1), epidermal growth factor receptor (EGFR), c-myc and Ras, as well as mutations of tumor-suppressor genes. It was found that the G870A polymorphism in exon 4 of the CCND1 gene may increase the risk of HBV-related HCC in the Chinese population (2). The chronic stimulation of EGFR plays a key role in the neoplastic conversion and development of HCC (3). A progressive increase in c-myc mRNA and protein was noted during the different steps of malignancy of HCC (4). Aberrant activation of different levels of the Ras pathway could play important roles in HCC. In addition, overexpression of H-ras, DNA copy number gains of B-Raf and hypermethylation of Ras binding proteins were found to be involved in the poor prognosis of HCC patients (5). However, due to the lack of effective diagnostic methods at the early stage of the disease, the mortality rate of HCC remains high. Therefore, it is crucial to understand the precise molecular mechanisms involved in the carcinogenesis, proliferation and recurrence of $\mathrm{HCC}$ and thus develop effective diagnostic and therapeutic strategies.

During the last decades, microarray technology and bioinformatic analysis have been widely used to screen genetic alterations at the genome level, which have helped us identify the differentially expressed genes (DEGs) and functional pathways involved in the carcinogenesis and progression of HCC. However, false-positive rates in independent microarray analysis make it difficult to obtain reliable results. Thus, in the present study, 3 mRNA microarray datasets from Gene Expression Omnibus (GEO) were downloaded and analyzed to obtain DEGs between liver cancer tissues and non-cancerous tissues. Subsequently, Gene Ontology (GO), Kyoto Encyclopedia of Genes and Genomes (KEGG) pathway enrichment analysis and protein-protein interaction (PPI) network analyses were performed to help us understand the molecular mechanisms underlying carcinogenesis and progression. In conclusion, a total of 273 DEGs and 16 hub genes were identified, which may be candidate biomarkers for HCC. 
$\mathbf{A}$

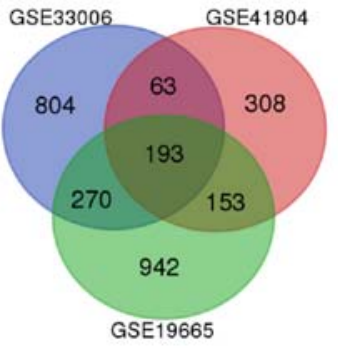

C

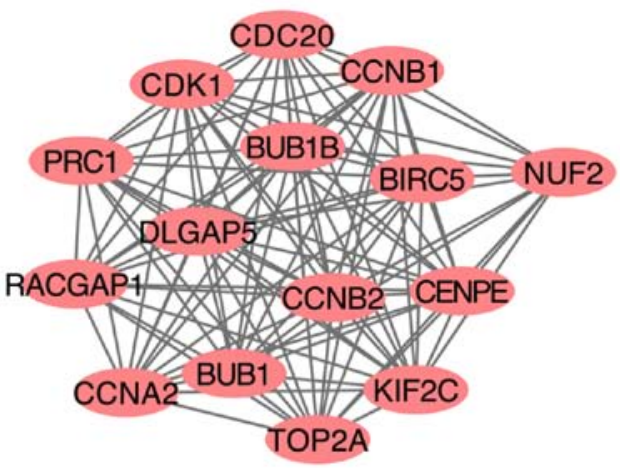

B

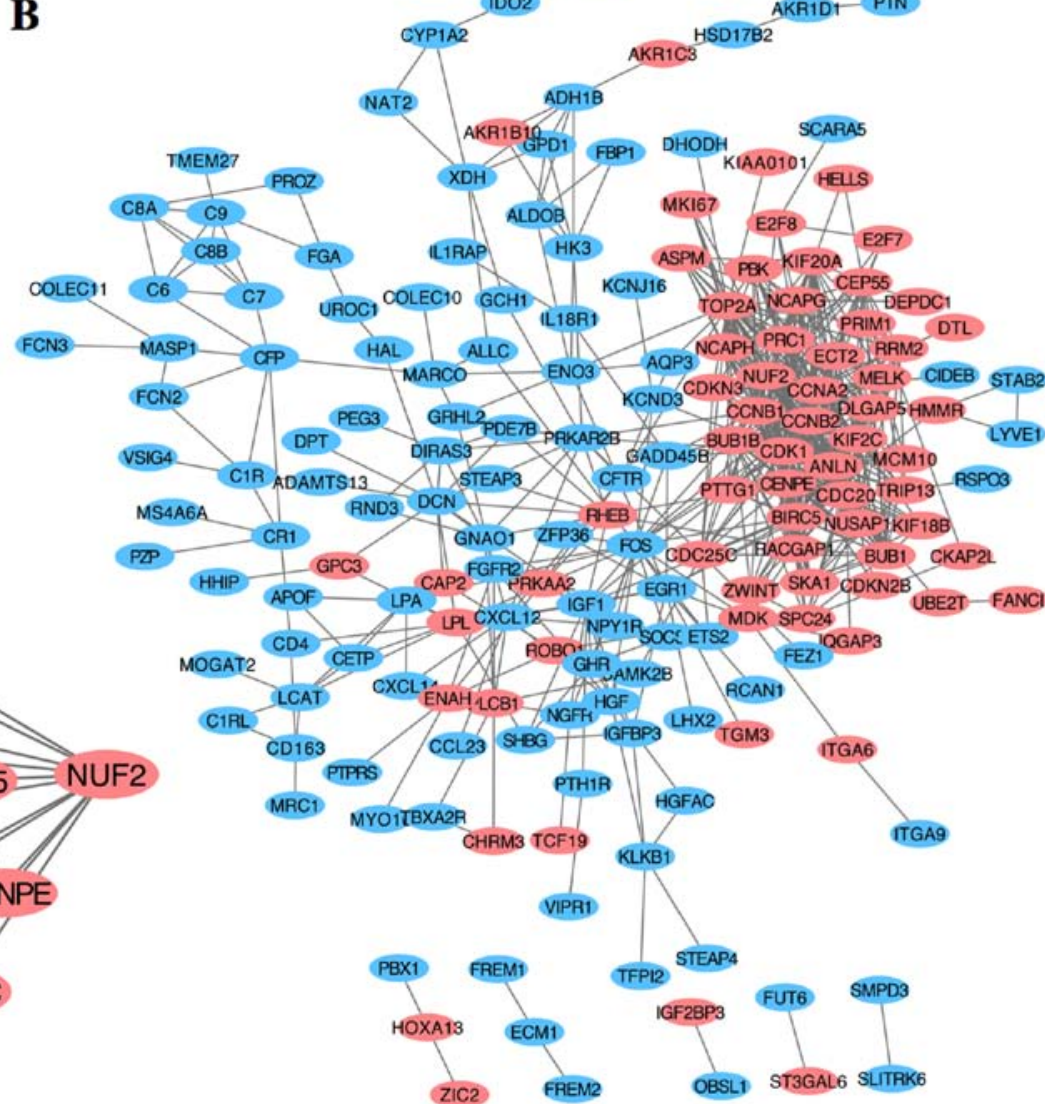

Figure 1. Venn diagram, PPI network and the most significant module of DEGs. (A) DEGs were selected with a fold change $>2$ and P-value $<0.01$ among the mRNA expression profiling sets GSE19665, GSE33006 and GSE41804. The 3 datasets showed an overlap of 273 genes. (B) The PPI network of DEGs was constructed using Cytoscape. (C) The most significant module was obtained from PPI network with 15 nodes and 102 edges. Upregulated genes are marked in light red; downregulated genes are marked in light blue.

\section{Materials and methods}

Microarray data. GEO (http://www.ncbi.nlm.nih.gov/geo) (6) is a public functional genomics data repository of high throughout gene expression data, chips and microarrays. Three gene expression datasets [GSE36668 (7), GSE18520 (8) and GSE14407 (9)] were downloaded from GEO (Affymetrix GPL570 platform, Affymetrix Human Genome U133 Plus 2.0 Array). The probes were converted into the corresponding gene symbol according to the annotation information in the platform. The GSE19665 dataset contained 10 HCC tissue samples and 10 non-cancerous samples. GSE33006 contained 3 HCC samples and 3 non-cancerous samples. GSE41804 contained $20 \mathrm{HCC}$ samples and 20 non-cancerous samples.

Identification of DEGs. The DEGs between HCC and non-cancerous samples were screened using GEO2R (http://www.ncbi.nlm.nih.gov/geo/geo2r). GEO2R is an interactive web tool that allows users to compare two or more datasets in a GEO series in order to identify DEGs across experimental conditions. The adjusted P-values (adj. P) and Benjamini and Hochberg false discovery rate were applied to provide a balance between discovery of statistically significant genes and limitations of false-positives. Probe sets without corresponding gene symbols or genes with more than one probe set were removed or averaged, respectively. $\operatorname{logFC}$ (fold change) $>1$ and adj. P-value $<0.01$ were considered statistically significant.

KEGG and GO enrichment analyses of DEGs. The Database for Annotation, Visualization and Integrated Discovery (DAVID; http://david.ncifcrf.gov) (version 6.7) (10) is an online biological information database that integrates biological data and analysis tools, and provides a comprehensive set of functional annotation information of genes and proteins for users to extract biological information. KEGG is a database resource for understanding high-level functions and biological systems from large-scale molecular datasets generated by high-throughput experimental technologies (11). GO is a major bioinformatics tool to annotate genes and analyze biological process of these genes (12). To analyze the function of DEGs, biological analyses were performed using DAVID online database. $\mathrm{P}<0.05$ was considered statistically significant.

PPI network construction and module analysis. The PPI network was predicted using Search Tool for the Retrieval of Interacting Genes (STRING; http://string-db.org) (version 10.0) (13) online database. Analyzing the functional interactions between proteins may provide insights into the mechanisms of generation or development of diseases. In the present study, PPI network of DEGs was constructed using STRING database, and an interaction with a combined 
Table I. GO and KEGG pathway enrichment analysis of DEGs in HCC samples.

\begin{tabular}{|c|c|c|c|}
\hline Term & Description & Count in gene set & P-value \\
\hline \multicolumn{4}{|l|}{ Downregulated } \\
\hline GO:0072376 & Protein activation cascade & 16 & $5.27 \mathrm{E}-15$ \\
\hline GO:0006956 & Complement activation & 14 & $5.47 \mathrm{E}-15$ \\
\hline GO:0006952 & Defense response & 41 & 2.24E-09 \\
\hline GO:0030246 & Carbohydrate binding & 13 & 0.00398 \\
\hline GO:0005537 & Mannose-binding & 4 & 0.0216 \\
\hline GO:0016491 & Oxidoreductase activity & 18 & 0.0216 \\
\hline GO:0005615 & Extracellular space & 42 & $1.89 \mathrm{E}-11$ \\
\hline GO:0005576 & Extracellular region & 80 & $2.41 \mathrm{E}-10$ \\
\hline GO:0044421 & Extracellular region part & 69 & $6.95 \mathrm{E}-09$ \\
\hline Hsa04610 & Complement and coagulation cascades & 10 & 1.37E-07 \\
\hline Hsa05020 & Prion diseases & 6 & 0.000106 \\
\hline Hsa00232 & Caffeine metabolism & 3 & 0.000665 \\
\hline Hsa01100 & Metabolic pathways & 25 & 0.00296 \\
\hline Hsa00010 & Glycolysis/gluconeogenesis & 5 & 0.00958 \\
\hline \multicolumn{4}{|l|}{ Upregulated } \\
\hline GO:0022402 & Cell cycle process & 45 & $4.36 \mathrm{E}-34$ \\
\hline GO:0007049 & Cell cycle & 48 & $9.01 \mathrm{E}-34$ \\
\hline GO:0000278 & Mitotic cell cycle & 41 & $6.08 \mathrm{E}-33$ \\
\hline GO:0000793 & Condensed chromosome & 15 & $3.67 \mathrm{E}-13$ \\
\hline GO:0005819 & Spindle & 17 & $3.67 \mathrm{E}-13$ \\
\hline GO:0005694 & Chromosome & 23 & $1.05 \mathrm{E}-12$ \\
\hline Hsa04110 & Cell cycle & 9 & 3.84E-07 \\
\hline Hsa04114 & Oocyte meiosis & 6 & 0.00058 \\
\hline Hsa04914 & Progesterone-mediated oocyte maturation & 5 & 0.00156 \\
\hline
\end{tabular}

GO, Gene Ontology; KEGG, Kyoto Encyclopedia of Genes and Genomes; DEGs, differentially expressed genes; HCC, hepatocellular carcinoma.

score $>0.4$ was considered statistically significant. Cytoscape (version 3.4.0) is an open source bioinformatics software platform for visualizing molecular interaction networks (14). The plug-in Molecular Complex Detection (MCODE) (version 1.4.2) of Cytoscape is an APP for clustering a given network based on topology to find densely connected regions (15). The PPI networks were drawn using Cytoscape and the most significant module in the PPI networks was identified using MCODE. The criteria for selection were as follows: MCODE scores $>5$, degree cut-off $=2$, node score cut-off=0.2, Max depth=100 and k-score=2. Subsequently, the KEGG and GO analyses for genes in this module were performed using DAVID.

Hub genes selection and analysis. The hub genes were selected with degrees $\geq 10$. A network of the genes and their co-expression genes was analyzed using cBioPortal (http://www.cbioportal. org) $(16,17)$ online platform. The biological process analysis of hub genes was performed and visualized using Biological Networks Gene Oncology tool (BiNGO) (version 3.0.3) plugin of Cytoscape (18). Hierarchical clustering of hub genes was constructed using UCSC Cancer Genomics Browser (http:// genome-cancer.ucsc.edu) (19). The overall survival and disease-free survival analyses of hub genes were performed using Kaplan-Meier curve in cBioPortal. The expression profiles of TOP2A and CDK1 were analyzed and displayed using online database Serial Analysis of Gene Expression (SAGE; http://www. ncbi.nlm.nih.gov/SAGE). The relationship between expression patterns and tumor grades, hepatitis virus infection status, satellites and vascular invasion were analyzed using online database Oncomine (http://www.oncomine.com) (20-22).

\section{Results}

Identification of DEGs in HCC. After standardization of the microarray results, DEGs $(1,558$ in GSE19665, 1,330 in GSE33006 and 717 in GSE41804) were identified. The overlap among the 3 datasets contained 273 genes as shown in the Venn diagram (Fig. 1A), consisting of 189 downregulated genes and 84 upregulated genes between liver cancer tissues and non-cancerous tissues.

$K E G G$ and $G O$ enrichment analyses of DEGs. To analyze the biological classification of DEGs, functional and pathway enrichment analyses were performed using DAVID. GO analysis results showed that changes in biological processes (BP) of DEGs were significantly enriched in protein activation cascade, complement activation, defense response, mitotic cell cycle and cell cycle process (Table I). Changes in molecular function (MF) were mainly enriched in carbohydrate binding, 

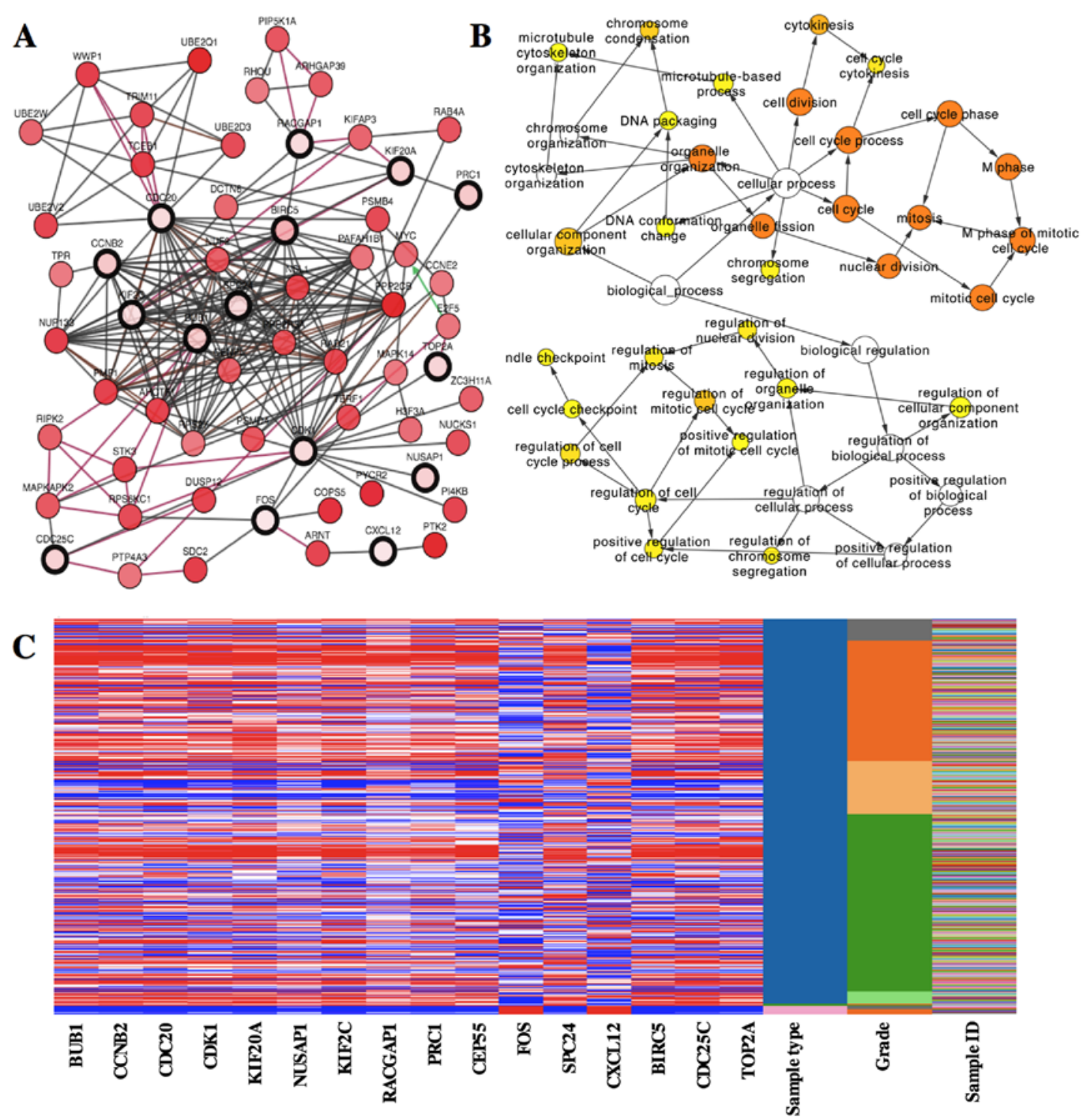

Figure 2. Interaction network and biological process analysis of the hub genes. (A) Hub genes and their co-expression genes were analyzed using cBioPortal. Nodes with bold black outline represent hub genes. Nodes with thin black outline represent the co-expression genes. (B) The biological process analysis of hub genes was constructed using BiNGO. The color depth of nodes refers to the corrected P-value of ontologies. The size of nodes refers to the numbers of genes that are involved in the ontologies. $\mathrm{P}<0.01$ was considered statistically significant. (C) Hierarchical clustering of hub genes was constructed using UCSC. The samples under the pink bar are non-cancerous samples and the samples under the blue bar are HCC samples. Upregulation of genes is marked in red; downregulation of genes is marked in blue.

oxidoreductase activity, mannose-binding, scavenger receptor activity and monosaccharide binding (Table I). Changes in cell component (CC) of DEGs were mainly enriched in the extracellular region, membrane attack complex and chromosome (Table I). KEGG pathway analysis revealed that the downregulated DEGs were mainly enriched in complement and coagulation cascades, glycolysis/gluconeogenesis and metabolic pathways, while the upregulated DEGs were mainly enriched in oocyte meiosis, cell cycle and progesterone-mediated oocyte maturation.

PPI network construction and module analysis. The PPI network of DEGs was constructed (Fig. 1B) and the most significant module was obtained using Cytoscape (Fig. 1C). The functional analyses of genes involved in this module were analyzed using DAVID. Results showed that genes in this module were mainly enriched in cell division, mitotic nuclear division and cell cycle (Table II).

Hub gene selection and analysis. A total of 16 genes were identified as hub genes with degrees $\geq 10$. The names, abbreviations and functions for these hub genes are shown in Table III. A network of the hub genes and their co-expression genes was analyzed using cBioPortal online platform (Fig. 2A). The biological process analysis of the hub genes is shown in Fig. 2B. Hierarchical clustering showed that the hub genes could basically differentiate the liver cancer samples from the noncancerous samples (Fig. 2C). Subsequently, the overall survival analysis of the hub genes was performed using Kaplan-Meier curve. HCC patients with BUB1, CCNB2, CDC20, CDK1, KIF20A, KIF2C, RACGAP1 and CEP55 alteration showed worse overall survival (Fig. 3A). Nonetheless, HCC patients 
Table II. GO and KEGG pathway enrichment analysis of DEGs in the most significant module.

\begin{tabular}{llrr}
\hline Pathway ID & \multicolumn{1}{c}{ Pathway description } & Count in gene set & FDR \\
\hline GO:0051301 & Cell division & 14 & $9.99 \mathrm{E}-19$ \\
GO:0000280 & Nuclear division & 13 & $4.42 \mathrm{E}-17$ \\
GO:0007067 & Mitotic nuclear division & 12 & $3.42 \mathrm{E}-16$ \\
GO: 1903047 & Mitotic cell cycle process & 13 & $1.75 \mathrm{E}-14$ \\
GO:0000278 & Mitotic cell cycle & 9 & $6.11 \mathrm{E}-14$ \\
GO:0005819 & Spindle & 7 & $7.60 \mathrm{E}-11$ \\
GO:0000793 & Condensed chromosome & 6 & $1.36 \mathrm{E}-08$ \\
GO:0000777 & Condensed chromosome kinetochore & 6 & $1.98 \mathrm{E}-08$ \\
GO:0000779 & Condensed chromosome, centromeric region & 10 & $2.18 \mathrm{E}-08$ \\
GO:0015630 & Microtubule cytoskeleton & 6 & $3.12 \mathrm{E}-08$ \\
Hsa04110 & Cell cycle & 4 & $5.20 \mathrm{E}-08$ \\
Hsa04914 & Progesterone-mediated oocyte maturation & 4 & $3.91 \mathrm{E}-05$ \\
Hsa04114 & Oocyte meiosis & $8.19 \mathrm{E}-05$ \\
\hline
\end{tabular}

GO, Gene Ontology; KEGG, Kyoto Encyclopedia of Genes and Genomes; DEGs, differentially expressed genes; FDR, false discovery rate.

Table III. Functional roles of 16 hub genes with degree $\geq 10$.

\begin{tabular}{|c|c|c|c|}
\hline No. & Gene symbol & Full name & Function \\
\hline 1 & BIRC5 & Baculoviral IAP repeat containing 5 & $\begin{array}{l}\text { BIRC5 may prevent apoptotic cell death } \\
\text { and is highly expressed in most tumors }\end{array}$ \\
\hline 2 & BUB1 & $\begin{array}{l}\text { BUB1 mitotic checkpoint serine/ } \\
\text { threonine kinase }\end{array}$ & BUB1 promotes the progression of breast cancer \\
\hline 3 & CCNB2 & Cyclin B2 & $\begin{array}{l}\text { CCNB2 (cyclin B2) is associated with invasion, } \\
\text { metastasis and poor prognosis of several cancers }\end{array}$ \\
\hline 4 & CDC20 & Cell division cycle 20 & $\begin{array}{l}\text { High expression of CDC } 20 \text { is associated with } \\
\text { development and progression of HCC }\end{array}$ \\
\hline 5 & $\mathrm{CDC} 25 \mathrm{C}$ & Cell division cycle $25 \mathrm{C}$ & $\mathrm{CDC} 25 \mathrm{C}$ can regulate the $\mathrm{G} 2 / \mathrm{M}$ transition in $\mathrm{HCC}$ cells \\
\hline 6 & CDK1 & Cyclin-dependent kinase 1 & $\begin{array}{l}\text { CDK1 can regulate the cell cycle progression, } \\
\text { apoptosis and carcinogenesis of tumor cells }\end{array}$ \\
\hline 7 & CEP55 & Centrosomal protein 55 & $\begin{array}{l}\text { High expression of CEP55 can promote the } \\
\text { proliferation of lung, breast and thyroid cancers }\end{array}$ \\
\hline 8 & CXCL12 & $\mathrm{C}-\mathrm{X}-\mathrm{C}$ motif chemokine ligand 12 & $\begin{array}{l}\text { High expression of CXCL12 in tumor cells } \\
\text { may impede tumor spread }\end{array}$ \\
\hline 9 & FOS & $\begin{array}{l}\text { FBJ murine osteosarcoma viral } \\
\text { oncogene homolog }\end{array}$ & $\begin{array}{l}\text { FOS has been implicated as a regulator of cell } \\
\text { proliferation, differentiation and transformation }\end{array}$ \\
\hline 10 & KIF20A & Kinesin family member $20 \mathrm{~A}$ & $\begin{array}{l}\text { High expression of KIF20A is involved in the } \\
\text { development and progression of various cancers }\end{array}$ \\
\hline 11 & NUSAP1 & $\begin{array}{l}\text { Nucleolar and spindle associated } \\
\text { protein } 1\end{array}$ & $\begin{array}{l}\text { High expression of NUSAP1 is involved in the } \\
\text { progression of prostate cancer }\end{array}$ \\
\hline 12 & KIF2C & Kinesin family member $2 \mathrm{C}$ & $\begin{array}{l}\mathrm{KIF} 2 \mathrm{C} \text { is overexpressed in various cancers and may be } \\
\text { associated with the chemoresistance of ovarian cancer }\end{array}$ \\
\hline 13 & RACGAP1 & Rac GTPase activating protein 1 & $\begin{array}{l}\text { RACGAP1 plays a regulatory role in cytokinesis, } \\
\text { cell growth and differentiation }\end{array}$ \\
\hline 14 & PRC1 & Protein regulator of cytokinesis 1 & $\begin{array}{l}\mathrm{PRC} 1 \text { may be a novel regulator of early } \mathrm{HCC} \\
\text { recurrence }\end{array}$ \\
\hline 15 & $\mathrm{SPC} 24$ & $\begin{array}{l}\text { SPC24, NDC80 kinetochore } \\
\text { complex component }\end{array}$ & $\begin{array}{l}\text { High expression of SPC } 24 \text { is associated with worse } \\
\text { disease-free survival and overall survival in HCC }\end{array}$ \\
\hline 16 & TOP2A & Topoisomerase (DNA) II $\alpha$ & $\begin{array}{l}\text { TOP } 2 \mathrm{~A} \text { acts as a target for several anticancer agents } \\
\text { and mutations of this gene have been associated with } \\
\text { drug resistance }\end{array}$ \\
\hline
\end{tabular}


A $\square$ Cases with alteration(s) in query gene(s)

Cases without alteration(s) in query gene(s)
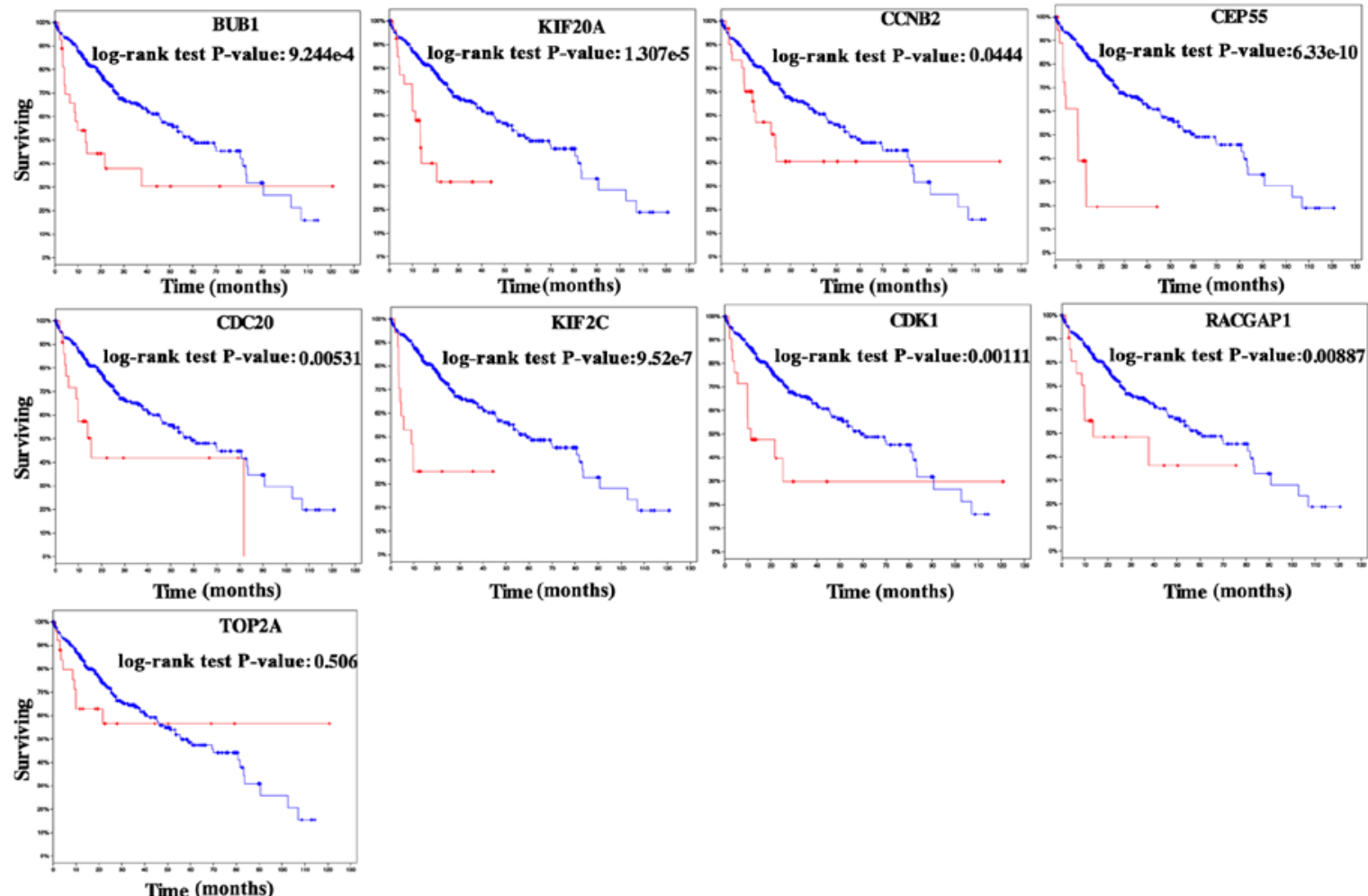

Time (months)

Time (months)

B $\square$ Cases with alteration(s) in query gene(s)

Cases without alteration(s) in query gene(s)
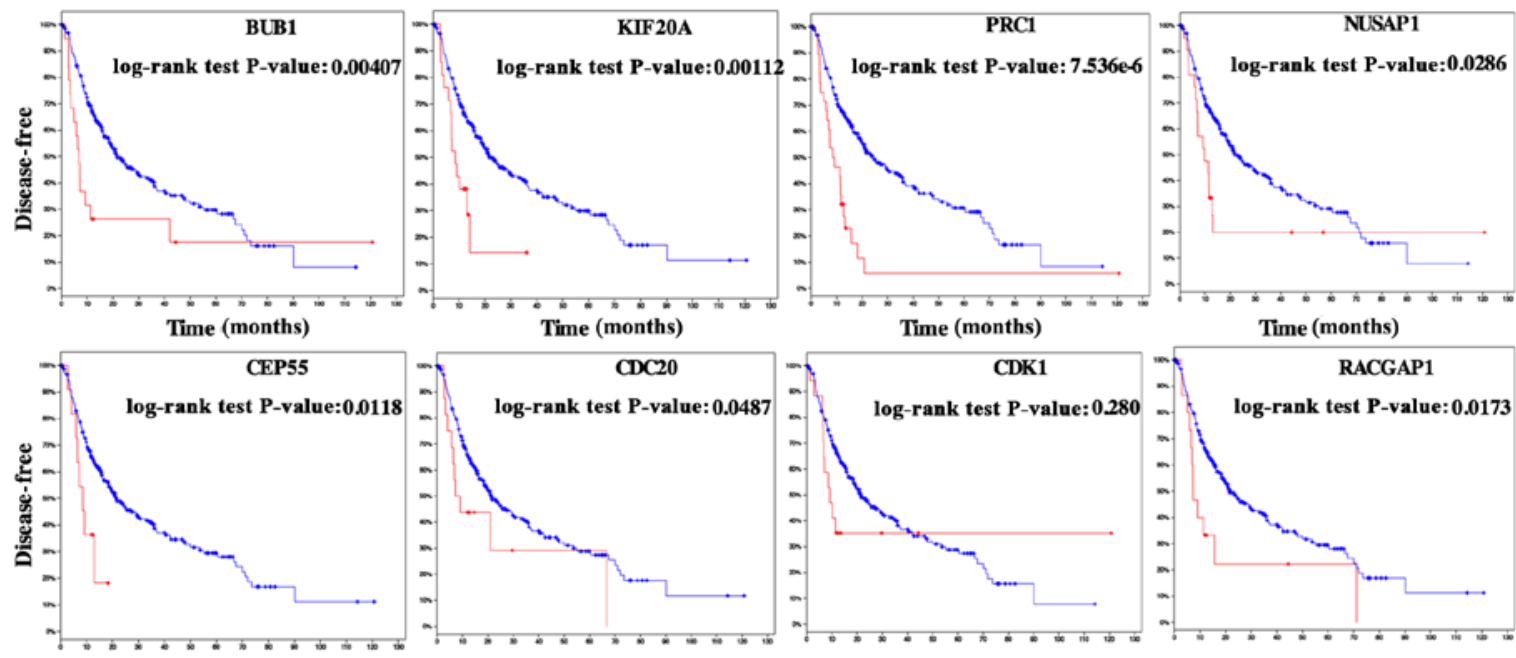

Time (months)

Time (months)

Time (months)
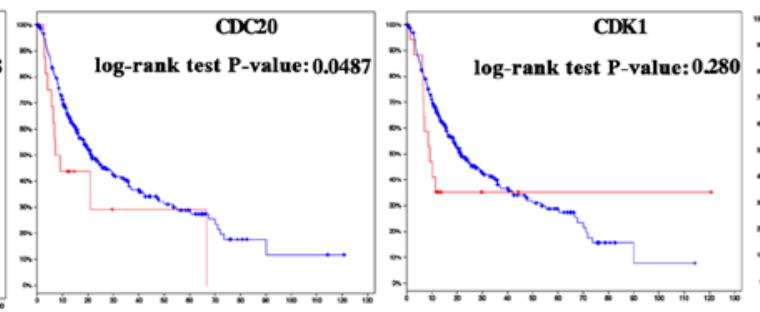

Time (months)

RACGAP1

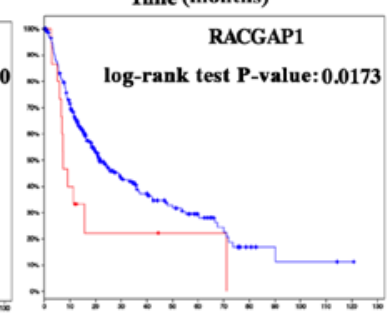

Time (months)

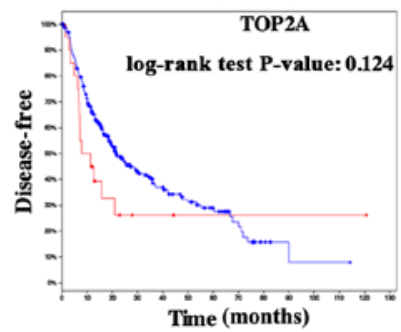

Time (months)

(1)

Figure 3. (A) Overall survival and (B) disease-free survival analyses of hub genes were performed using cBioPortal online platform. $\mathrm{P}<0.05$ was considered statistically significant.

with BUB1, CDC20, KIF20A, NUSAP1, RACGAP1, PRC1 and CEP55 alteration showed worse disease-free survival (Fig. 3B).
Among these genes, TOP2A and CDK1 showed the highest node degrees with 33 , suggesting that they may play important 
$\mathbf{A}$

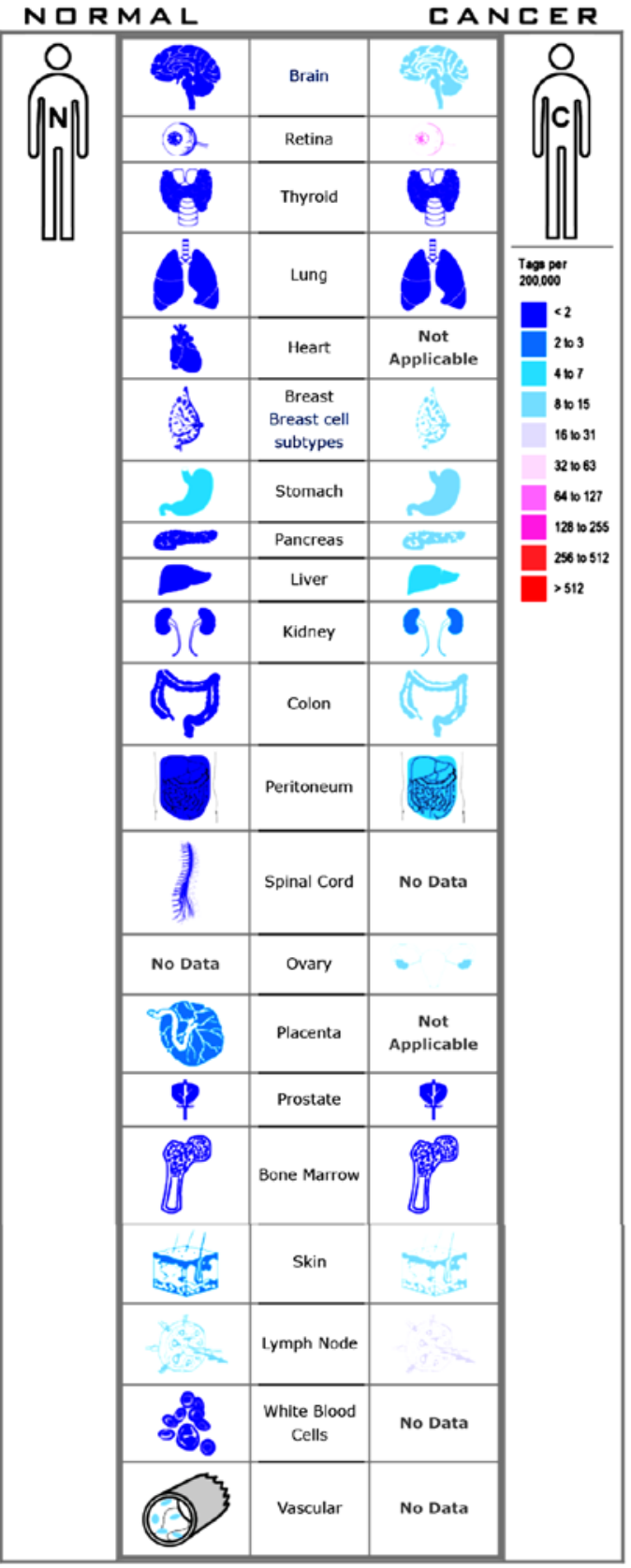

B

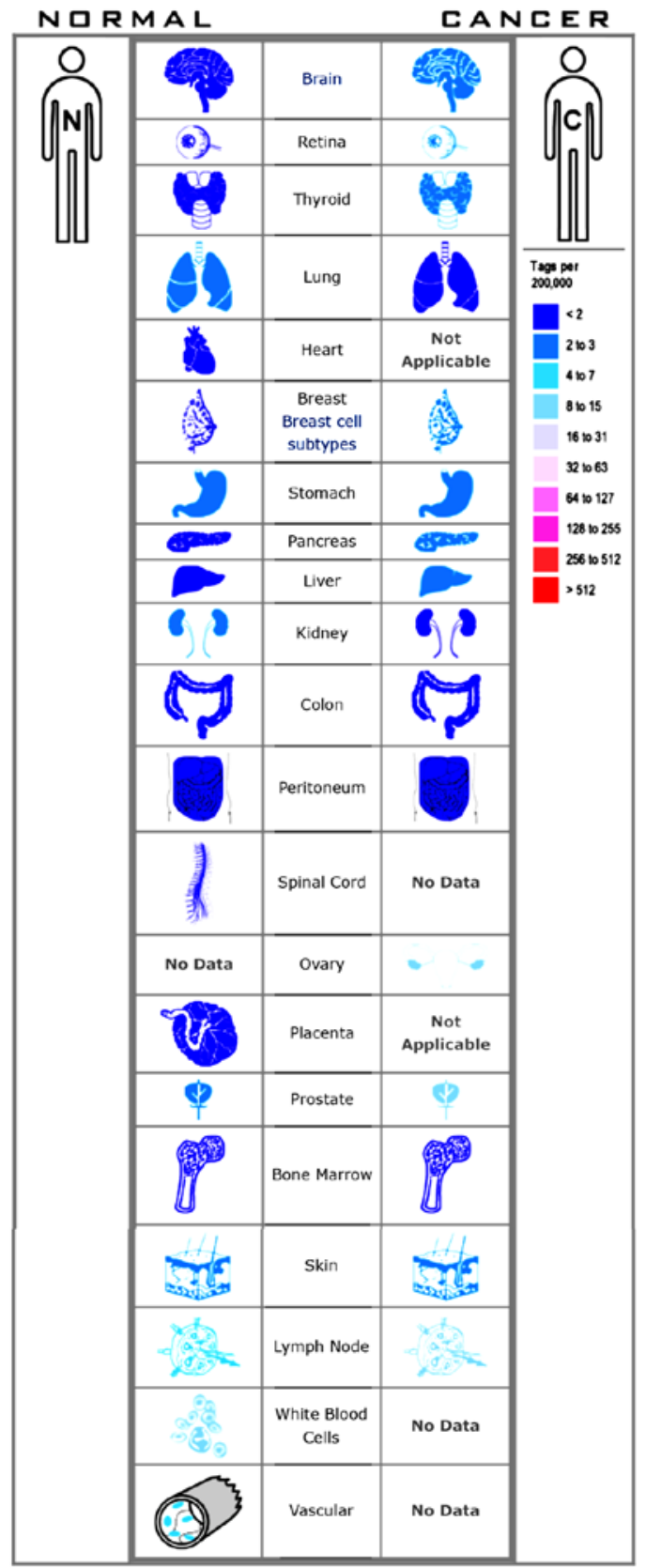

Figure 4. Expression profiles for (A) TOP2A and (B) CDK1 in human cancers analyzed using SAGE.

$\mathbf{A}$

\begin{tabular}{|ccc|c|c|c|c|}
\hline Median rank & P-value & \multicolumn{5}{|l|}{ Gene } \\
\hline 25.0 & $3.60 E-13$ & TOP2A & & \multicolumn{3}{|l|}{} \\
\cline { 4 - 7 } & & & 1 & 2 & 3 & 4 \\
\cline { 5 - 7 } & & & &
\end{tabular}

$\mathbf{B}$

\begin{tabular}{|c|c|c|c|c|c|c|}
\hline Median rank & P-value & Gene & & & & \\
\hline \multirow[t]{2}{*}{61.0} & $2.87 \mathrm{E}-10$ & CDK1 & & & & \\
\hline & & & 1 & 2 & 3 & 4 \\
\hline
\end{tabular}

1. $P$-value $=5.34 \mathrm{E}-22$ fold change $=2.663$

2. - -value $=1.93 \mathrm{E}-13$ fold change $=11.236$

3. $\mathrm{P}$-value $=\mathbf{2 . 0 3 E - 8 5}$ fold change $=\mathbf{8 . 2 9 2}$

4. $P$-value $=7.20 \mathrm{E}-13$ fold change $=13.321$

1. $\mathrm{P}$-value $=6.41 \mathrm{E}-29$ fold change $=4.148$ 2. $\mathrm{P}$-value $=9.36 \mathrm{E}-10$ fold change $=\mathbf{5 . 8 0 8}$ 3. $\mathrm{P}$-value $=1.05 \mathrm{E}-84$ fold change $=5.573$ 4. $P$-value $=5.74 \mathrm{E}-10$ fold change $=8.680$

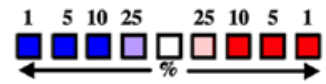

Figure 5. Oncomine analysis of cancer vs. normal tissue of (A) TOP2A and (B) CDK1. Heat maps of TOP2A and CDK1 gene expression in clinical hepatocellular carcinoma samples vs. normal tissues. 1. Hepatocellular carcinoma vs. normal liver, Chen, Mol Biol Cell, 2002 (20). 2. Hepatocellular carcinoma vs. normal liver, Roessler, Cancer Res, 2010 (21). 3. Hepatocellular carcinoma vs. normal liver, Roessler, Cancer Res, 2010 (21). 4 . Hepatocellular carcinoma vs. normal liver, Wurmbach, Hepatology, 2007 (22). 

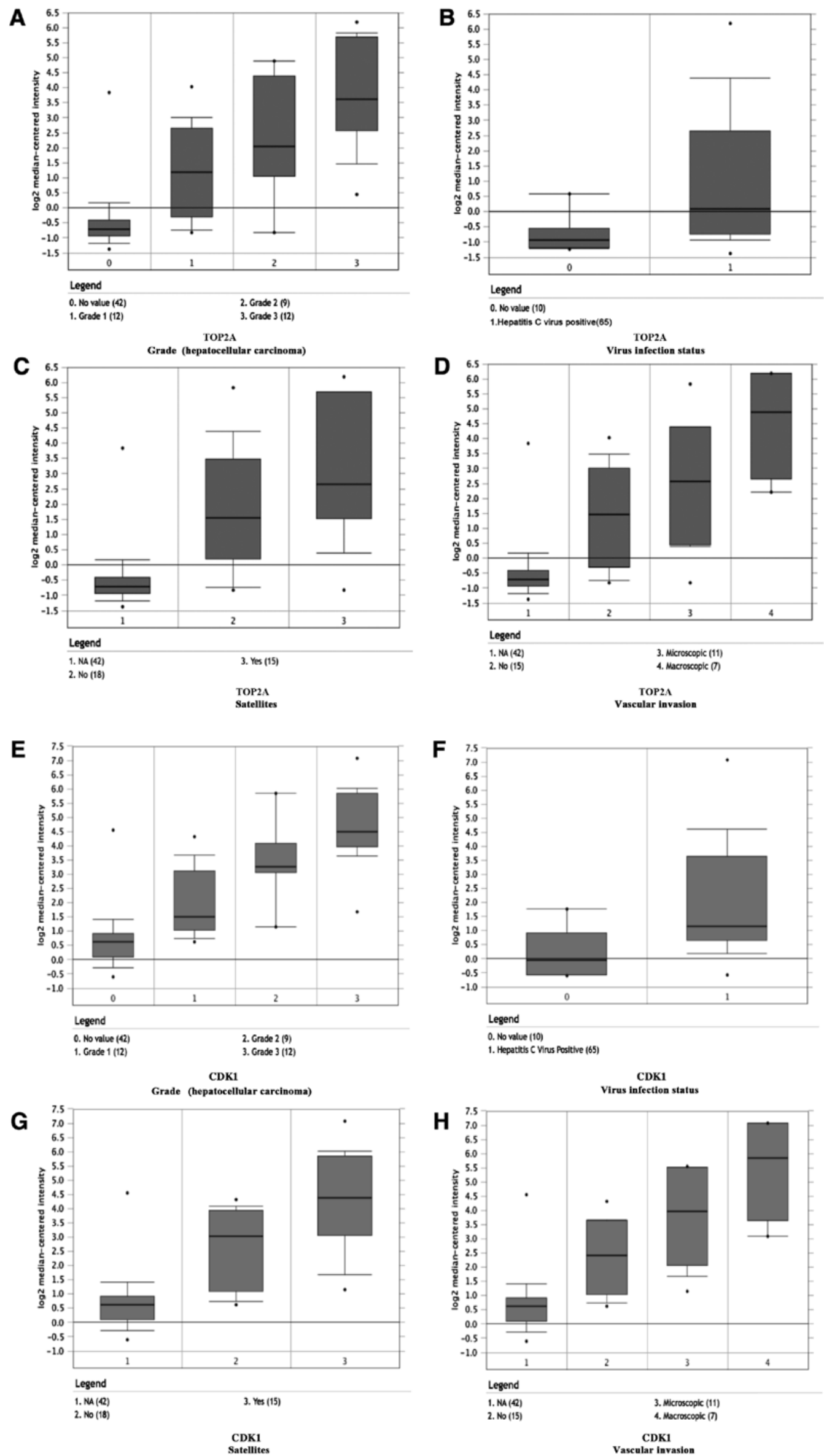

Figure 6. Association between the expression of TOP2A and CDK1 and tumor grade, hepatitis virus infection status, satellites and vascular invasion in the Wurmbach Liver dataset. (A-D) TOP2A mRNA expression in HCC compared to normal liver tissues. (E-H) CDK1 mRNA expression in hepatocellular carcinoma samples. 
roles in the carcinogenesis or progression of HCC. Using the data from cBioPortal, we noted that $\mathrm{HCC}$ patients who had an association of genomic alterations in TOP2A showed reductions in overall and disease-free survival. However, those observations were not statistically significant $(\mathrm{P}=0.506$ for overall survival and $\mathrm{P}=0.124$ for disease-free survival). In addition, the CDK1 alteration was significantly associated with worse overall survival but not disease-free survival $(\mathrm{P}=0.00111$ for overall survival and $\mathrm{P}=0.280$ for disease-free survival) (Fig. 3B). The expression profile of TOP2A and CDK1 in human tissue was displayed using SAGE. We found that TOP2A mRNA in brain, retina, breast, pancreas, liver, kidney, colon and peritoneum displayed higher levels as compared with the matched normal tissues (Fig. 4A). CDK1 mRNA in brain, retina, thyroid, breast, pancreas, liver and prostate displayed higher levels as compared with the matched normal tissues (Fig. 4B). Oncomine analysis of cancer vs. normal tissue showed that TOP2A and CDK1 were significantly overexpressed in HCC in the different datasets (Fig. 5A and B). In the Wurmbach Liver dataset, higher mRNA levels of TOP2A and CDK1 were associated with tumor grade, hepatitis virus infection status, satellites and vascular invasion (Fig. 6A-H).

\section{Discussion}

Hepatocellular carcinoma (HCC) is the fifth most common malignant tumor worldwide and its mortality rate has increased in recent years (1). The main etiology factors of HCC include chronic infection with hepatitis viruses, gene mutations, cell damage, alcoholic liver diseases and aflatoxin poisoning (23). The most common cause is chronic infection with hepatitis $\mathrm{B}$ virus (HBV) or hepatitis $\mathrm{C}$ virus (HCV), accounting for over $80 \%$ of HCC cases. However, the molecular mechanisms of HCC remain poorly understood. Cell cycle regulators play important roles in HCC. Mutation of cyclin D1 (CCND1), c-myc or Ras, hypermethylation of cyclin D2 (CCND2) promoter and aberrant expression of $\mathrm{p} 53$ or $\mathrm{p} 21$ have been reported to be involved in HCC $(24,25)$. In addition, splicing alterations of NT5E, Sulf1 or SLC39A14 have been reported to be associated with HCC (26-28). Most cases of HCC without an early finding are not candidates for curative therapies, which may be one of the reasons for the poor patient prognosis. Thus, potential markers for diagnosis and treatment with high efficiency are urgently demanded. Microarray technology enables us to explore the genetic alterations in HCC, and has been proved to be a useful approach to identify new biomarkers in other diseases.

In the present study, 3 mRNA microarray datasets were analyzed to obtain DEGs between liver cancer tissues and non-cancerous tissues. A total of 273 DEGs were identified among the 3 datasets, including 189 downregulated genes and 84 upregulated genes. GO and KEGG enrichment analyses were performed to explore interactions among the DEGs. The upregulated genes were mainly enriched in oocyte meiosis, mitotic cell cycle and cell cycle, while the downregulated genes were mainly enriched in protein activation cascade, complement activation and complement and coagulation cascades. Previous studies have reported that dysregulation of the cell cycle process and mitotic cell cycle play important roles in the carcinogenesis or progression of tumors $(24,25,29)$. In addition, recent studies have brought forward a tumor-promoting role for complement activation (30). Moreover, oxidoreductase activity often plays a major role in antioxidant defense and can encode tumor suppressors that are frequently altered in tumors $(31,32)$. In a word, all these theories are consistent with our results. GO enrichment analysis revealed that changes in the most significant modules were mainly enriched in cell division, nuclear division and mitotic cell cycle process, while changes in KEGG were mainly enriched in cell cycle, progesterone-mediated oocyte maturation and oocyte meiosis.

We selected 16 DEGs as hub genes with degrees $\geq 10$. Among these hub genes, TOP2A and CDK1 showed the highest node degrees with 33. TOP2A, which forms breaks in double-stranded DNA and alters DNA structure during transcription, has been shown to be correlated with early age onset, microvascular invasion, shorter patient survival, chemoresistance and recurrence in $\operatorname{HCC}(33,34)$. Thus, it is regarded as a target for anticancer agents, such as epirubicin, doxorubicin, etoposide and temozolomide (35-37). In HER2-amplified breast cancer, HER2 and TOP2A genes are frequently co-amplified (38). However, TOP2A overexpression in HCC is independent from HER2 amplification or overexpression (39). In addition, TOP2A overexpression has also been found in lung, colon and ovarian cancers, and may be regarded as a valuable biomarker for diagnosis, treatment and prognosis of tumors (40-42). In the present study, PPI network showed that TOP2A directly interacts with CDK1, RACGAP1, BIRC5 and PRC1, indicating a key role of TOP2A in HCC. Cyclin-dependent kinase 1 (CDK1), a serine/threonine kinase, regulates cell cycle progression by binding to cyclin $\mathrm{B}$ to form a complex called cyclin B-CDK1. miR-582-5p was found to regulate the progression of $\mathrm{HCC}$ by inhibiting the expression of CDK1 (43). CDK1 overexpression has also been found in lung, pancreas and other cancers. In addition to its role in cell cycle progression, cyclin B-CDK1 could interact with apoptin and regulate the subcellular localization of apoptin, leading to apoptosis and carcinogenesis (44). Survivin inactivates and blocks CDK1 by increasing the level of Weel and thus, inactivates and blocks the pro-apoptotic activity of CDK1 (45). Cyclin B-CDK1 is also involved in connecting mitotic arrest and apoptosis by mediating the phosphorylation of anti-apoptotic Bcl-2 (46). We assessed the expression of TOP2A and $\mathrm{CDK} 1$ in relation to overall and disease-free survival. Gene alteration in TOP2A showed reductions in overall and diseasefree survival. However, in the present study, those observations were not statistically significant. In addition, the CDK1 alteration was significantly associated with worse overall survival, but not disease-free survival. Nevertheless, several clinical studies have shown that overexpression of TOP2A is significantly associated with shorter survival times $(37,39)$. We speculate that the reason may be that survival analyses in cBioPortal were performed on the basis of the relationship between gene mutation and prognosis, while gene overexpression usually arises from mutation or amplification. Thus, overexpression of TOP2A in HCC may arise from gene amplification rather than mutation, and further research is needed to confirm our hypothesis. Oncomine analysis showed that higher mRNA levels of TOP2A and CDK1 were associated with tumor grade, hepatitis virus infection status, satellites and vascular invasion, indicating vital roles of TOP2A and CDK1 in the carcinogenesis or progression of HCC. 
RACGAP1, a Rac- and Cdc42-specific GAP, can suppress Rac and activate RhoA, leading to the promotion of pseudopod extension and invasion (47). Moreover, RACGAP1 shows a relationship with AURKA, a negative prognostic indicator in gastric cancer (48). BIRC5, also called survivin, is overexpressed and plays important roles in cell division and proliferation in a majority of cancers including HCC. PRC1 is involved in the microtubule organization in eukaryotes and is upregulated in breast tumors (49). Recent research has found that it can be a novel regulator of early $\mathrm{HCC}$ recurrence via potentiating Wnt signaling (50). High expression of CDC20 is associated with sex, differentiation, tumor-node-metastasis (TNM) stage, and p53 expression of HCC (51). The protein kinase CDC25C acts as an activator of cyclin B-CDK1 that regulates the G2/M transition in HCC cells (52). HCC patients with relatively low CXCL12 mRNA levels exhibit worse overall survival (53). A recent study found that the transcriptional activity of c-FOS could be induced by membrane melanoma cell adhesion molecule (MCAM), and it is important for MCAM-induced liver tumorigenesis (54). High expression of SPC24 is associated with worse disease-free and overall survival in HCC patients (55). High expression of KIF20A is involved in the development and progression of various cancers such as pancreatic, bladder and breast cancer. A recent study found that the glioma-associated oncogene 2/KIF20A axis is crucial for the proliferation of human HCC cells (56).

Literature retrieval results showed that the interaction among HCC and hub genes NUSAP1, CEP55, BUB1, CCNB2, KIF2C and RACGAP1 has not been widely reported. NUSAP1 regulates mitosis, and high expression of NUSAP1 is involved in the progression of prostate cancer (57). CEP55 is a centrosome-associated protein, which plays an important role in regulating the cell cycle. Overexpression of CEP55 was found to promote the proliferation of several cancers, such as pulmonary adenocarcinoma, breast cancer and anaplastic thyroid carcinoma (58-60). BUB1, a component of the spindle assembly checkpoint, is overexpressed and plays important roles in the progression of breast cancer (61). However, BUB1 has been reported to have a controversial role in spindle assembly checkpoint activation $(62,63)$, which needs further investigation. CCNB2 is overexpressed in bladder, lung and colorectal cancers, and is associated with invasion, metastasis and poor prognosis of cancers $(64,65)$. KIF2C plays an important role in the segregation of chromosomes in mitosis, and is overexpressed in various cancers and may be associated with the chemoresistance of ovarian cancer $(66,67)$. In addition, we also performed hierarchical clustering for hub genes. Results showed that these hub genes differentiated HCC samples from non-cancerous samples, and may be candidates for diagnostic biomarkers. Moreover, alteration of BUB1, CDC20, KIF20A, RACGAP1 and CEP55 is involved in worse overall and disease-free survival, indicating that these genes may play important roles in the carcinogenesis, progression, invasion or recurrence of $\mathrm{HCC}$.

In conclusion, the present study was designed to identify DEGs that may be involved in the carcinogenesis or progression of HCC. A total of 273 DEGs and 16 hub genes were identified and may be regarded as diagnostic biomarkers for HCC. However, further studies are needed to elucidate the biological function of these genes in HCC.

\section{Acknowledgements}

The present study was supported by a grant (no. 81271838) from the National Science Foundation of China.

\section{References}

1. El-Serag HB and Rudolph KL: Hepatocellular carcinoma: Epidemiology and molecular carcinogenesis. Gastroenterology 132: 2557-2576, 2007.

2. Hu Z, Zhou Z, Xiong G, Wang Y, Lai Y, Deng L and Yang J: Cyclin D1 G870A polymorphism and the risk of hepatocellular carcinoma in a Chinese population. Tumour Biol 35: 5607-5612, 2014.

3. Berasain C, Castillo J, Prieto J and Avila MA: New molecular targets for hepatocellular carcinoma: The ErbB1 signaling system. Liver Int 27: 174-185, 2007.

4. Gan FY, Gesell MS, Alousi M and Luk GD: Analysis of ODC and c-myc gene expression in hepatocellular carcinoma by in situ hybridization and immunohistochemistry. J Histochem Cytochem 41: 1185-1196, 1993.

5. Newell P, Toffanin S, Villanueva A, Chiang DY, Minguez B, Cabellos L, Savic R, Hoshida Y, Lim KH, Melgar-Lesmes P, et al: Ras pathway activation in hepatocellular carcinoma and anti-tumoral effect of combined sorafenib and rapamycin in vivo. J Hepatol 51: 725-733, 2009.

6. Edgar R, Domrachev M and Lash AE: Gene Expression Omnibus: NCBI gene expression and hybridization array data repository. Nucleic Acids Res 30: 207-210, 2002.

7. Elgaaen BV, Olstad OK, Sandvik L, Odegaard E, Sauer T, Staff AC and Gautvik KM: ZNF385B and VEGFA are strongly differentially expressed in serous ovarian carcinomas and correlate with survival. PLoS One 7: e46317, 2012.

8. Mok SC, Bonome T, Vathipadiekal V, Bell A, Johnson ME, Wong KK, Park DC, Hao K, Yip DK, Donninger H, et al: A gene signature predictive for outcome in advanced ovarian cancer identifies a survival factor: Microfibril-associated glycoprotein 2. Cancer Cell 16: 521-532, 2009.

9. Bowen NJ, Walker LD, Matyunina LV, Logani S, Totten KA, Benigno BB and McDonald JF: Gene expression profiling supports the hypothesis that human ovarian surface epithelia are multipotent and capable of serving as ovarian cancer initiating cells. BMC Med Genomics 2: 71, 2009.

10. Huang DW, Sherman BT, Tan Q, Collins JR, Alvord WG, Roayaei J, Stephens R, Baseler MW, Lane HC and Lempicki RA: The DAVID Gene Functional Classification Tool: A novel biological module-centric algorithm to functionally analyze large gene lists. Genome Biol 8: R183, 2007.

11. Kanehisa M: The KEGG database. Novartis Found Symp 247: 91-252, 2002

12. Ashburner M, Ball CA, Blake JA, Botstein D, Butler $\mathrm{H}$, Cherry JM, Davis AP, Dolinski K, Dwight SS, Eppig JT, et al; Gene ontology: Tool for the unification of biology. The Gene Ontology Consortium. Nat Genet 25: 25-29, 2000.

13. Franceschini A, Szklarczyk D, Frankild S, Kuhn M, Simonovic M, Roth A, Lin J, Minguez P, Bork P, von Mering C, et al: STRING v9.1: Protein-protein interaction networks, with increased coverage and integration. Nucleic Acids Res 41: D808-D815, 2013.

14. Smoot ME, Ono K, Ruscheinski J, Wang PL and Ideker T: Cytoscape 2.8: New features for data integration and network visualization. Bioinformatics 27: 431-432, 2011.

15. Bandettini WP, Kellman P, Mancini C, Booker OJ, Vasu S, Leung SW, Wilson JR, Shanbhag SM, Chen MY and Arai AE: MultiContrast Delayed Enhancement (MCODE) improves detection of subendocardial myocardial infarction by late gadolinium enhancement cardiovascular magnetic resonance: A clinical validation study. J Cardiovasc Magn Reson 14: 83, 2012.

16. Gao J, Aksoy BA, Dogrusoz U, Dresdner G, Gross B, Sumer SO, Sun Y, Jacobsen A, Sinha R, Larsson E, et al: Integrative analysis of complex cancer genomics and clinical profiles using the cBioPortal. Sci Signal 6: pl1, 2013.

17. Cerami E, Gao J, Dogrusoz U, Gross BE, Sumer SO, Aksoy BA, Jacobsen A, Byrne CJ, Heuer ML, Larsson E, et al: The cBio cancer genomics portal: An open platform for exploring multidimensional cancer genomics data. Cancer Discov 2: 401-404, 2012. 
18. Maere S, Heymans K and Kuiper M: BiNGO: A Cytoscape plugin to assess overrepresentation of gene ontology categories in biological networks. Bioinformatics 21: 3448-3449, 2005.

19. Kent WJ, Sugnet CW, Furey TS, Roskin KM, Pringle TH, Zahler AM and Haussler D: The human genome browser at UCSC. Genome Res 12: 996-1006, 2002.

20. Chen X, Cheung ST, So S, Fan ST, Barry C, Higgins J, Lai KM, Ji J, Dudoit S, Ng IO, et al: Gene expression patterns in human liver cancers. Mol Biol Cell 13: 1929-1939, 2002.

21. Roessler S, Jia HL, Budhu A, Forgues M, Ye QH, Lee JS, Thorgeirsson SS, Sun Z, Tang ZY, Qin LX, et al: A unique metastasis gene signature enables prediction of tumor relapse in early-stage hepatocellular carcinoma patients. Cancer Res 70: 10202-10212, 2010.

22. Wurmbach E, Chen YB, Khitrov G, Zhang W, Roayaie S, Schwartz M, Fiel I, Thung S, Mazzaferro V, Bruix J, et al: Genome-wide molecular profiles of HCV-induced dysplasia and hepatocellular carcinoma. Hepatology 45: 938-947, 2007.

23. Turner PC, Sylla A, Diallo MS, Castegnaro JJ, Hall AJ and Wild CP: The role of aflatoxins and hepatitis viruses in the etiopathogenesis of hepatocellular carcinoma: A basis for primary prevention in Guinea-Conakry, West Africa. J Gastroenterol Hepatol 17 (Suppl): S441-S448, 2002.

24. Wang Y, Cheng J, Xu C, Liu S, Jiang S, Xu Q, Chen X, Zhuang H and Lu F: Quantitative methylation analysis reveals gender and age differences in p16INK4a hypermethylation in hepatitis B virus-related hepatocellular carcinoma. Liver Int 32: 420-428, 2012.

25. Choi YL, Park SH, Jang JJ and Park CK: Expression of the G1-S modulators in hepatitis B virus-related hepatocellular carcinoma and dysplastic nodule: Association of cyclin D1 and p53 proteins with the progression of hepatocellular carcinoma. J Korean Med Sci 16: 424-432, 2001

26. Snider NT, Altshuler PJ, Wan S, Welling TH, Cavalcoli J and Omary MB: Alternative splicing of human NT5E in cirrhosis and hepatocellular carcinoma produces a negative regulator of ecto-5'-nucleotidase (CD73). Mol Biol Cell 25: 4024-4033, 2014

27. Gill RBS, Day A, Barstow A, Zaman G, Chenu C and Dhoot GK Mammalian Sulf1 RNA alternative splicing and its significance to tumour growth regulation. Tumour Biol 33: 1669-1680, 2012.

28. Franklin RB, Levy BA, Zou J, Hanna N, Desouki MM, Bagasra O, Johnson LA and Costello LC: ZIP14 zinc transporter downregulation and zinc depletion in the development and progression of hepatocellular cancer. J Gastrointest Cancer 43: 249-257, 2012.

29. Tripathi V, Shen Z, Chakraborty A, Giri S, Freier SM, Wu X, Zhang Y, Gorospe M, Prasanth SG, Lal A, et al: Long noncoding RNA MALAT1 controls cell cycle progression by regulating the expression of oncogenic transcription factor B-MYB. PLoS Genet 9: e1003368, 2013.

30. Markiewski MM and Lambris JD: Unwelcome complement. Cancer Res 69: 6367-6370, 2009.

31. Abu-Remaileh M and Aqeilan RI: The tumor suppressor WW domain-containing oxidoreductase modulates cell metabolism. Exp Biol Med 240: 345-350, 2015.

32. Roszczenko P, Radomska KA, Wywial E, Collet JF and Jagusztyn-Krynicka EK: A novel insight into the oxidoreductase activity of Helicobacter pylori HP0231 protein. PLoS One 7: e46563, 2012.

33. Watanuki A, Ohwada S, Fukusato T, Makita F, Yamada T, Kikuchi A and Morishita Y: Prognostic significance of DNA topoisomerase IIalpha expression in human hepatocellular carcinoma. Anticancer Res 22: 1113-1119, 2002.

34. Nakajima T, Yasui K, Zen K, Inagaki Y, Fujii H, Minami M, Tanaka S, Taniwaki M, Itoh Y, Arii S, et al: Activation of B-Myb by E2F1 in hepatocellular carcinoma. Hepatol Res 38: 886-895, 2008

35. Chan HH, Chu TH, Chien HF, Sun CK, Wang EM, Pan HB, Kuo $\mathrm{HM}, \mathrm{Hu} \mathrm{TH}$, Lai KH, Cheng JT, et al: Rapid induction of orthotopic hepatocellular carcinoma in immune-competent rats by non-invasive ultrasound-guided cells implantation. BMC Gastroenterol 10: 83, 2010.

36. Wang N, Zhu M, Tsao SW, Man K, Zhang Z and Feng Y: MiR-23a-mediated inhibition of topoisomerase 1 expression potentiates cell response to etoposide in human hepatocellular carcinoma. Mol Cancer 12: 119, 2013

37. Wong N, Yeo W, Wong WL, Wong NL, Chan KY, Mo FK, Koh J, Chan SL, Chan AT, Lai PB, et al: TOP2A overexpression in hepatocellular carcinoma correlates with early age onset, shorter patients survival and chemoresistance. Int J Cancer 124: 644-652, 2009.
38. Fritz P, Cabrera CM, Dippon J, Gerteis A, Simon W, Aulitzky WE and van der Kuip H: c-erbB2 and topoisomerase IIalpha protein expression independently predict poor survival in primary human breast cancer: A retrospective study. Breast Cancer Res 7: R374-R384, 2005.

39. Panvichian R, Tantiwetrueangdet A, Angkathunyakul N and Leelaudomlipi S: TOP2A amplification and overexpression in hepatocellular carcinoma tissues. Biomed Res Int 2015: 381602, 2015.

40. Dingemans AM, Witlox MA, Stallaert RA, van der Valk P, Postmus PE and Giaccone G: Expression of DNA topoisomerase IIalpha and topoisomerase IIbeta genes predicts survival and response to chemotherapy in patients with small cell lung cancer. Clin Cancer Res 5: 2048-2058, 1999.

41. Lazaris AC, Kavantzas NG, Zorzos HS, Tsavaris NV and Davaris PS: Markers of drug resistance in relapsing colon cancer. J Cancer Res Clin Oncol 128: 114-118, 2002.

42. Costa MJ, Hansen CL, Holden JA and Guinee D Jr: Topoisomerase II alpha: Prognostic predictor and cell cycle marker in surface epithelial neoplasms of the ovary and peritoneum. Int J Gynecol Pathol 19: 248-257, 2000.

43. Zhang Y, Huang W, Ran Y, Xiong Y, Zhong Z, Fan X, Wang Z and Ye Q: miR-582-5p inhibits proliferation of hepatocellular carcinoma by targeting CDK1 and AKT3. Tumour Biol 36: 8309-8316, 2015

44. Zhao J, Han SX, Ma JL, Ying X, Liu P, Li J, Wang L, Zhang Y, Ma J, Zhang L, et al: The role of CDK1 in apoptin-induced apoptosis in hepatocellular carcinoma cells. Oncol Rep 30: 253-259, 2013.

45. Guzman JR, Fukuda S and Pelus LM: Inhibition of caspase- 3 by Survivin prevents Weel Kinase degradation and promotes cell survival by maintaining phosphorylation of $\mathrm{p} 34 \mathrm{Cdc} 2$. Gene Ther Mol Biol 13B: 264-273, 2009.

46. Terrano DT, Upreti $M$ and Chambers TC: Cyclin-dependent kinase 1-mediated $\mathrm{Bcl}-\mathrm{x}_{\mathrm{I}} / \mathrm{Bcl}-2$ phosphorylation acts as a functional link coupling mitotic arrest and apoptosis. Mol Cell Biol 30: 640-656, 2010.

47. Jacquemet G, Green DM, Bridgewater RE, von Kriegsheim A Humphries MJ, Norman JC and Caswell PT: RCP-driven $\alpha 5 \beta 1$ recycling suppresses Rac and promotes RhoA activity via the RacGAP1-IQGAP1 complex. J Cell Biol 202: 917-935, 2013.

48. Bornschein J, Nielitz J, Drozdov I, Selgrad M, Wex T, Jechorek D, Link A, Vieth $\mathrm{M}$ and Malfertheiner P: Expression of aurora kinase A correlates with the Wnt-modulator RACGAP1 in gastric cancer. Cancer Med 5: 516-526, 2016.

49. Subramanian R, Ti SC, Tan L, Darst SA and Kapoor TM: Marking and measuring single microtubules by PRC1 and kinesin-4. Cell 154: 377-390, 2013

50. Chen J, Rajasekaran M, Xia H, Zhang X, Kong SN, Sekar K, Seshachalam VP, Deivasigamani A, Goh BK, Ooi LL, et al: The microtubule-associated protein PRC1 promotes early recurrence of hepatocellular carcinoma in association with the Wnt/ $\beta$-catenin signalling pathway. Gut 65: 1522-1534, 2016.

51. Li J, Gao JZ, Du JL, Huang ZX and Wei LX: Increased CDC20 expression is associated with development and progression of hepatocellular carcinoma. Int J Oncol 45: 1547-1555, 2014.

52. Deng LJ, Peng QL, Wang LH, Xu J, Liu JS, Li YJ, Zhuo ZJ, Bai LL, Hu LP, Chen WM, et al: Arenobufagin intercalates with DNA leading to $G_{2}$ cell cycle arrest via ATM/ATR pathway. Oncotarget 6: 34258-34275, 2015.

53. Semaan A, Dietrich D, Bergheim D, Dietrich J, Kalff JC, Branchi V, Matthaei H, Kristiansen G, Fischer HP and Goltz D: CXCL12 expression and PD-L1 expression serve as prognostic biomarkers in HCC and are induced by hypoxia. Virchows Arch 470: 185-196, 2017.

54. Wang J, Tang X, Weng W, Qiao Y, Lin J, Liu W, Liu R, Ma L, $\mathrm{Yu}$ W, Yu Y, et al: The membrane protein melanoma cell adhesion molecule (MCAM) is a novel tumor marker that stimulates tumorigenesis in hepatocellular carcinoma. Oncogene 34: 5781-5795, 2015

55. Zhu P, Jin J, Liao Y, Li J, Yu XZ, Liao W and He S: A novel prognostic biomarker SPC24 up-regulated in hepatocellular carcinoma. Oncotarget 6: 41383-41397, 2015.

56. Shi C, Huang D, Lu N, Chen D, Zhang M, Yan Y, Deng L, Lu Q, $\mathrm{Lu} \mathrm{H}$ and Luo S: Aberrantly activated Gli2-KIF20A axis is crucial for growth of hepatocellular carcinoma and predicts poor prognosis. Oncotarget 7: 26206-26219, 2016.

57. Gordon CA, Gulzar ZG and Brooks JD: NUSAP1 expression is upregulated by loss of RB1 in prostate cancer cells. Prostate 75: 517-526, 2015 . 
58. Jiang W, Wang Z, Chen G and Jia Y: Prognostic significance of centrosomal protein 55 in stage I pulmonary adenocarcinoma after radical resection. Thorac Cancer 7: 316-322, 2016

59. Wang Y, Jin T, Dai X and Xu J: Lentivirus-mediated knockdown of CEP55 suppresses cell proliferation of breast cancer cells. Biosci Trends 10: 67-73, 2016.

60. Weinberger P, Ponny SR, Xu H, et al: Cell cycle M-phase genes are highly upregulated in anaplastic thyroid carcinoma. Thyroid 27: 236-252, 2017.

61. Wang Z, Katsaros D, Shen Y, Fu Y, Canuto EM, Benedetto C, Lu L, Chu WM, Risch HA and Yu H: Biological and clinical significance of $M A D 2 L 1$ and $B U B 1$, genes frequently appearing in expression signatures for breast cancer prognosis. PLoS One 10: e0136246, 2015.

62. Kawashima SA, Yamagishi Y, Honda T, Ishiguro $\mathrm{K}$ and Watanabe Y: Phosphorylation of $\mathrm{H} 2 \mathrm{~A}$ by Bub1 prevents chromosomal instability through localizing shugoshin. Science 327: 172-177, 2010.

63. London $\mathrm{N}$ and Biggins S: Mad1 kinetochore recruitment by Mps1-mediated phosphorylation of Bub1 signals the spindle checkpoint. Genes Dev 28: 140-152, 2014.
64. Takashima S, Saito H, Takahashi N, Imai K, Kudo S, Atari M, Saito Y, Motoyama S and Minamiya Y: Strong expression of cyclin B2 mRNA correlates with a poor prognosis in patients with non-small cell lung cancer. Tumour Biol 35: 4257-4265, 2014.

65. Lei CY, Wang W, Zhu YT, Fang WY and Tan WL: The decrease of cyclin B2 expression inhibits invasion and metastasis of bladder cancer. Urol Oncol 34: 237.e1-237.e10, 2016.

66. Zhao F, Siu MK, Jiang L, Tam KF, Ngan HY, Le XF, Wong OG, Wong ES, Gomes AR, Bella L, et al: Overexpression of forkhead box protein M1 (FOXM1) in ovarian cancer correlates with poor patient survival and contributes to paclitaxel resistance. PLoS One 9: e113478, 2014

67. Shimo A, Tanikawa C, Nishidate T, Lin ML, Matsuda K, Park JH, Ueki T, Ohta T, Hirata K, Fukuda M, et al: Involvement of kinesin family member $2 \mathrm{C} /$ mitotic centromere-associated kinesin overexpression in mammary carcinogenesis. Cancer Sci 99: 62-70, 2008. 